\title{
THE ECLIPSE AND REBIRTH OF AMERICAN PHILOSOPHICAL PLURALISM: A HISTORY LESSON ABOUT HISTORY
}

\begin{abstract}
The 1950s and '60s saw a struggle in American academic philosophy between a philosophical tradition that maintained a central role for the history of philosophy along with an openness to diverse philosophical methods and an ascendant analytic approach that marginalized its own history and restricted the scope of philosophy to self-generated philosophical problems. Columbia University in this period, while marked by these tensions, still provided a fertile ground for generating teacher-philosophers whose pedagogy reflected a deep and serious respect for history and philosophical pluralism. John Herman Randall Jr. and Justus Buchler were two of the central figures who fostered such an environment in Columbia's Philosophy Department. Joseph P. Fell was a product of this environment and brought these traits to his classroom at Bucknell University. Playing off of Hegel's insights into history, this essay will reflect upon the philosophies of Randall and Buchler with an eye toward pedagogy, especially as recalled in classes taught by Fell. The subtext of these reflections will provide a commentary on trends within academic philosophy in America over the last 40 years.
\end{abstract}

Keywords: history of philosophy, pluralism, pedagogy, Columbia University, G. W. F. Hegel, John Herman Randall, Jr., Justus Buchler, Joseph P. Fell.

The 1950 s and ' 60 s saw a struggle in American academic philosophy between a historically grounded and pluralistic philosophical tradition and an ascendant analytic approach that marginalized its own history and restricted the scope of philosophy to selfgenerated philosophical problems. For half a century American philosophy had maintained a central role for the history of philosophy while at the same time demonstrating openness to diverse philosophical methods. The post-war years saw a significant shift taking place. Columbia University in this period, while marked by these tensions, still provided a fertile ground for generating teacher-philosophers whose pedagogy reflected a deep and serious respect for history and philosophical pluralism. This respect was also reflected in the life and career of the Armenian Academician Georg Brutian. John Herman Randall Jr. and Justus Buchler were two of the central figures who fostered such an environment in Columbia's Philosophy Department. Joseph P. Fell, my first mentor in philosophy, was a product of this environment and brought these traits to his classroom in Bucknell University. This essay is a brief reflection upon the philosophies of Randall and Buchler with an eye 
toward pedagogy. The subtext of these reflections will provide a commentary on trends within academic philosophy in American over the course of the last 40 years.

The mid-point of twentieth century marked a fundamental moment of transition for philosophy as practiced in American academia. Partially as a result of the influx of European philosophers in the post-World War II period and the rapid expansion of scientific knowledge with its benefits and dangers, the categories of the American philosophical landscape were changing. Idealism, Realism, Naturalism, and Pragmatism, were no longer sufficient to capture this landscape. Philosophy in America shifted its focus to issues and developments in logical and linguistic analysis that stemmed from the influence of the Vienna Circle and from the work of philosophers such as Bertrand Russell, G. E. Moore, Ludwig Wittgenstein, and J. L. Austin in Great Britain. To a somewhat lesser extent, some philosophers in America turned their attention to work in phenomenology and existentialism that had its primary home in Germany and France. By the time this transitional period ended in the 1960s, many philosophy departments, especially in the major doctoral granting institutions, had become less pluralistic and had relegated history of philosophy to a less central role in the curriculum.

Illustrative of this shift are the remarks of two of America's leading philosophers of the mid-twentieth century, John Herman Randall, Jr. and Willard Van Orman Quine. The former, nearing the end of his distinguished career at Columbia University by the 1960s, while the latter rising to the first ranks of philosophical prestige at Harvard University, can be illustrative of this shift. Randall in a
1958 volume titled, Nature and Historical Experience, republished an essay first written in the mid-1930s. In that essay titled, "Historical Naturalism," Randall writes:

It is obvious we must inquire into our world in its temporal dimensions: we must understand our past, the past that made us what we are and still constitutes us, the past that is an essential part of our present world. Our culture that is changing is itself the precipitate of a long series of changes; and these our materials and our tools can only be understood in terms of the past changes that forced men to create them. To know what our ideas meant at their birth enables us to understand better what they have become . . . (Randall, 1958, pp. 4-5).

Nearly 20 years later while still early in his career, Quine in sharp contrast writes:

Philosophy is in large part concerned with the theoretical, non-genetic underpinnings of scientific theory; with what science could get along with, could be reconstructed by means of, as distinct from what science has historically made use of. If certain problems of ontology, say, or modality, or causality, or contrary-tofact conditionals, which arise in ordinary language, turn out not to arise in science as reconstituted with the help of formal logic, then those philosophical problems have in an important sense been solved: they have been shown not to be implicated in any necessary foundation of science. Such solutions are good to just the extent that (a) philosophy of science is philosophy enough and (b) the refashioned logical underpinnings of science do not engender new philosophical problems 
of their own (Quine, 1953, p. 446) [emphasis added].

In his more than half century of teaching, Quine only taught one course in the history of philosophy, a course on the philosophy of David Hume.

Randall's choice, maybe at Buchler's urging, to begin his volume with the above quoted essay can be seen as a response to logical positivism and the narrow empirical basis upon which it is founded. Randall's prescient warnings in his reprinted 1930s essay were certainly not being heeded as academic philosophy "progressed" into the decade of the 1960s. He further writes in the same essay:

Philosophies of experience which start with experience as a subject-matter are in fact starting with certain ideas of experience, and that those which end with experience as a conclusion are in fact ending with a certain experience of ideas. And a whole range of philosophies, including most of those called empirical, stand condemned as inadequate, unenlightened, and blind. We must start with tradition, and we must end with tradition criticized, clarified, and enlarged (Randall, 1958, p. $10)$.

Randall's concerns with the growing neglect of history may well have motivated him to explicitly examine the issue of how philosophy deals with its own past. The resulting 1961 Machette Lectures, subsequently published under the title of How Philosophy Uses Its Past, is a small yet profoundly important book that should be essential reading for all would-be philosophers. Another Columbia colleague of Randall who voiced a similar concern in the 1940s was John Dewey. In a new, at the time not yet published, preface to his seminal work, Experience and Nature, Dewey proposed retitling his book, "Culture and Nature," in order to avoid the ahistorical and narrowed appropriation of the term "experience" endemic to the then rising tide of Anglo-American empiricism. For Dewey, culture has a history, while experience is often misinterpreted and limited to a here and now.

Justus Buchler, in this same period, was developing metaphysics of experience that jettisoned some of the traditional vocabulary that was stymying the understanding of the broadened naturalistic philosophy of his Columbia colleagues, Dewey and Randall. Toward a General Theory of Human Judgment in 1951 marked the introduction of his concept of "proception" as an alternative to the shopworn concept of experience. Buchler did not elaborate upon the genesis of this concept at the time but years later in a new introduction to the second edition of the book he conceptually tackled the history of the shortcomings of the concept of experience that necessitated this reconceptualization (Buchler, 1979). Dewey's own dissatisfaction with the term "experience" was mirrored, though on different metaphysical grounds, by Buchler's own criticism of the term and its replacement with a more conceptually precise yet metaphysically general term, "proception." The distinctly human relationship with the world that would become his concept of proception was thus based upon a deep critique of the history of philosophy. Buchler had often taught a course, both at Columbia and then again at the State University of New York at Stony Brook, that examined the history of the philosophical use of the term "experience." He approached this concept historically, beginning with Hume and Locke and tracing it through to 
twentieth century philosophers in both the Anglo-American and Continental traditions. Working out ideas through a critical examination of the history of philosophy was a trait shared by both of my most important philosophical mentors, Justus Buchler and Joseph P. Fell. While Buchler rarely presented his own philosophical system in his classroom teaching, you could clearly see its origins in the careful analyses and critiques that constituted the core of the historical subject matter we examined.

Joseph P. Fell's courses also reflected this deep regard for the necessity of working through the historical tradition in order to make sense of the contemporary philosophical problems that are the grist of the present-day philosophical mill. In Fell's introductory philosophy course from the fall of 1970 one can see this in evidence. The course titled, "Five Types of Philosophy," provided a historical approach to what Fell labels, "Spiritualism," "Naturalism," "Dualism," "Idealism," and "Pragmatism." On the blackboard the first day of class was the following quotation from $\mathrm{G}$. W. F. Hegel; a quote I could not fully appreciate at the time and still today is well-worth pondering:

The living spirit that dwells in philosophy demands, in order to reveal itself, to be born again by a kindred spirit. Before an historical attitude that, prompted by some interest, is after information about opinions, it passes by as a strange phenomenon without revealing its inside.

Hegel's words have prompted me to probe further into what I did not understand at the time. I have now discovered that the quoted passage was from Hegel's essay, "The Differ- ence Between Fichte's and Schelling's System of Philosophy." I now see that Hegel was expressing his attitude toward how the history of philosophy should play a role in philosophy itself. In this essay he calls those who misunderstand the historical approach to the history of philosophy, "the curious collector[s] of information." Those who have little time or tolerance for philosophers who labor on the history of philosophy sometimes display a distained dismissal toward such activity captured in in Hegel's characterization of the "curious collector." History of philosophy is for them a collection of mostly false curiosities. Collecting opinions from the past is not the approach Hegel nor Fell and Buchler advocated. Picking up from where the quotation left off, Hegel goes on to claim:

It matters little to the spirit that it is forced to augment the extant collection of mummies and the general heap of contingent oddities; for the spirit itself slipped away between the fingers of the curious collector of information. The collector stands firm in his neutral attitude towards truth; he preserves his independence whether he accepts opinions, rejects them, or abstains from decision. He can give philosophical systems only one relation to himself: they are opinions - and such incidental things as opinions can do him no harm. He has not learned that there is truth to be had (Hegel, 1977, p.86).

These "mummies and the general heap of contingent oddities" must have been what Fell had in mind when on our second class meeting he uttered: "Human outlooks are more determinate in a philosophy than are facts or data. They determine what facts are explored" 
("Class lecture", 1970) It is curious that these two sentences are the only notes that I bothered to write down that day; yet they do capture the essence of Fell and Buchler's approach to philosophical pedagogy.

Contrary to Quine's quip that "philosophy of science is philosophy enough," Hegel goes on in this same passage quoted above to elaborate upon the connection between the history of philosophy and science:

The history of philosophy [seems to] acquire a more useful aspect, however, when the impulse to enlarge science takes hold of it, for according to Reinhold, the history of philosophy should serve as a means "to penetrate more profoundly than ever into the spirit of philosophy, and to develop the idiosyncratic views of one's predecessors about the grounding of the reality of human cognition further in new views of one's own." Only if this sort of information concerning previous attempts to solve the problem of philosophy were available could the attempt actually succeed in the end - if mankind is fated to succeed in it at all (Hegel, 1977, p. 86).

The connections I have drawn between Randall and Hegel could also have been made with other important philosophers in the tradition. Randall was, as was his mentor and teacher, Frederick J. E. Woodbridge, a great admirer and exponent of the Aristotelian method of conceptual analysis. Whether it was the concept of cause or that of human arête, we always begin by first turning to our predecessors and their "previous attempts to solve the problem[s] of philosophy." As earlier quoted from Randall: "We must start with tradition, and we must end with tradition criticized, clarified, and enlarged."

This method of reading the philosophical tradition with the goal of ending with "tradition criticized, clarified, and enlarged," marked the philosophical pedagogy of Randall, Buchler and Fell. The brilliantly crafted historical writings of Randall in his twovolume tour-de-force, The Career of Philosophy (Randall, 1962-65), epitomized this approach. This is a work that continues to play an important role in my career as professor of philosophy and one that I would recommend to others who teach historically oriented courses.

I would like to conclude on a personal note. I have had the fortune, though I sometimes think the misfortune, of spending thirty years of my teaching career at one university. The fortunate side of my career comes from the fact that the philosophy department I joined was both pluralistic in philosophical orientation and strongly committed to the history of philosophy. We have a mandatory four-course sequence in history plus required courses that take up important figures in twentieth century philosophy. We have managed to maintain our commitment to history while at the same time building our strengths in a variety of applied areas of philosophy such as computer ethics, business ethics, biomedical ethics, environmental philosophy, gender studies, etc. It is heartening to see that philosophers from across the philosophical spectrum, whether they are trained in the Pragmatist, Continental or Analytic traditions, are contributing in important ground-breaking ways to these applied areas in philosophy. While the academic profession of philosophy 
has become more pluralistic and relevant to the global human predicament, its existence is threatened now more than ever. As with many disciplines in the humanities, the last decade has been one in which we have increasing been forced to defend what we do and how we do it. As one who sees himself aligned to the Pragmatist school of philosophy, I have no problem with innovating our curriculum to achieve better outcomes for all our students, whether they are majoring in philosophy or not. What I am troubled by is a deemphasizing of the humanities and a narrowing focus on what are called the STEM disciplines (science, technology, engineering and math). Politicians and administrators who only have their eye on the financial bottom line and workforce training often decry the need for courses in the liberal education core, calling them a luxury we can no longer afford. Under this mindset, philosophy, art history, literature, creative writing courses must make way for courses that train our students for the technological future they all will face. Yet it is precisely in these courses in the humanities that we critically engage with history. The critical and creative response to how thinkers have thought in the past is the source of innovation in the future. This is a lesson borne out across many fields of human endeavor and one that lay at the heart of the education I re- ceived from the philosophers who trace themselves back to philosophy as it was practiced at Columbia University half a century ago.

\section{REFERENCES}

Buchler, J. (1979). Toward a General Theory of Human Judgment (2nd revised ed.). New York: Dover Publications.

Class lecture, Philosophy 101B, Bucknell University, September 9, 1970.

Hegel, G.W.F. (1977) The Difference Between Fichte's and Schelling's System of Philosophy, (Translation of Differenz des Fichte'schen und Schelling'schen Systems der Philosophie) (H. S. Harris \& W. Cerf Trans.). Albany: SUNY Press.

Quine, V.W. (Oct., 1953). Mr. Strawson on Logical Theory, Mind, Vol. 62, No. 248.

Randall, J.H. Jr. (1958), Nature and Historical Experience: Essays in Naturalism and in the Theory of History, New York: Columbia University Press. The essay, "Historical Naturalism" originally published in 1935.

Randall, J.H. Jr. (1962-65), The Career of Philosophy. Vol. 1 \& 2. New York: Columbia University Press. 